\title{
Experimental determination of the stress-crack opening relation in fibre cementitious composites with a crack-tip singularity
}

\author{
V. C. LI, M. MAALEJ, T. HASHIDA \\ Advanced Civil Engineering Materials Research Laboratory, Department of Civil and \\ Environmental Engineering, University of Michigan, Ann Arbor, MI 48109-2125, USA
}

A $J$-based-fracture-testing method is presented for determining the bridging-stress-crackopening-displacement $(\sigma-\delta)$ relationship in fibre-reinforced composites where the crack-tip toughness is not negligible. The $J$-based technique originally proposed for concrete has been well-established for cementitious composites where the fracture process is primarily dominated by the formation of a fracture-process zone and the contribution of the crack-tip toughness is negligibly small. In this study, the $J$-based technique is further extended to cover materials for which the crack-tip stress singularity coexists with the fracture-process zone. This extended version of the $J$-based technique explicitly accounts for the crack-tip singularity while considering the fracture-process zone. This newly derived testing technique has been applied to a high-strength-mortar (HSM) reinforced with carbon and steel fibres where the fibrebridging toughness can be of the same order of magnitude as the crack-tip toughness. The validity of the $\sigma-\delta$ relationships deduced has been examined by comparing with results obtained from direct uniaxial tension tests. It is suggested that the $\mathrm{J}$-based-fracture-testing technique can provide reasonable $\sigma-\delta$ relationships and fracture parameters in a fibrereinforced HSM.

\section{Introduction}

Applications of high-strength concrete are a leading factor in the advancement of building technology today. It can be shown, for example, that highstrength concrete has allowed the construction of higher multi-storey buildings and has resulted in tremendous savings on these buildings; this is due mainly to the reduced foundation cost resulting from reductions in structural-member size and weight. The structural and economic advantages of high-strength concrete have motivated considerable efforts devoted towards the enhancement of its mechanical properties. It is currently possible to reach strengths of the order of $80-100 \mathrm{~N} \mathrm{~mm}^{-2}$ using normal processing and curing procedures.

Unfortunately, despite significant processing advances, several factors are currently limiting confidence in the end-user and hence in broader applications of high-strength concrete. First, high-strength concrete has been found to be more brittle and notch sensitive than normal-strength concrete $[1-3]$, so that additional steel reinforcement or steel jacketing is required to prevent brittle fracture; this often offsets the advantage of using high-strength concrete. In addition, a survey of the literature reveals that there are only a few fracture-toughness data for concrete with compressive strengths above $60 \mathrm{~N} \mathrm{~mm}^{-2}$. Therefore, further developments in the use of high-strength concrete and in the mechanical-performance predic- tion of structural components call for a reliable testing technique for determining the fracture properties germane to designs which prevent catastrophic brittle failure. The reliable use of high-strength concrete can only be achieved when a suitable fracture-testing methodology has been established based on a theoretically sound foundation in conjunction with the development of numerical simulation methods. One way of overcoming the brittleness of high-strength concrete may be to introduce fibres into the matrix. It has been convincingly demonstrated that significant toughness enhancement can be obtained by correct fibre reinforcement in normal-strength concrete.

It is well-accepted that crack propagation in cementitious materials and in their composites is controlled by the formation of a crack-bridging zone behind the crack tip. This bridging zone is often referred to as the fracture-process zone. Because of its dominant role, it is crucially important to determine the law that governs the formation of the fracture-process zone (that is, the bridging-stress-crack-opening relationship).

To characterize fracture-process-zone growth, we shall employ the cohesive crack model [4] and determine the bridging-stress-crack-opening-displacement $(\sigma-\delta)$ relationship by means of a $J$-based-fracturetesting technique. As will be clear later, the bridging toughness can be of the same order of magnitude as the crack-tip toughness in a high-strength mortar, and 
in some of its fibre-reinforced composites, so that the crack-tip singular term cannot be neglected. In this regard, the $J$-based testing technique, originally proposed by Li et al. [5], is further developed in this paper in order to explicitly account for the crack-tip singularity while considering the bridging-process zone. The theoretical background behind the technique is briefly summarized in Section 2. The data-analysis procedure and experimental results for high-strength mortar reinforced with fibres are then reported.

\section{A brief description of the $J$-based technique}

This section provides the principle of the extended $J$-based technique. Li et al. [5] have proposed a novel $J$-based-fracture-testing technique to determine the tension-softening relationship used originally for characterizing concrete-fracture behaviour. This testing technique has the advantage of requiring only a simple stroke-controlled loading machine and it is relatively stable in comparison with direct uniaxial tensile tests. Since this proposal, the $J$-based technique has undergone extensive development. It has been applied by several researchers to a number of quasibrittle materials (including concrete [6], fibre reinforced concrete [7-9] and rock [10-11]) in which the fracture process is primarily dominated by the formation of a fracture-process zone and in which the contribution of the crack-tip singularity to the total fracture energy is negligibly small.

A schematic of the stress distribution around the crack tip is presented in Fig. Ia for a material where the crack-tip singularity coexists with the fractureprocess zone. The development of the fracture-process zone is characterized by a relationship between the stress, $\sigma$, and the crack-opening displacement, $\delta$. This corresponds to the fictitious crack-process zone

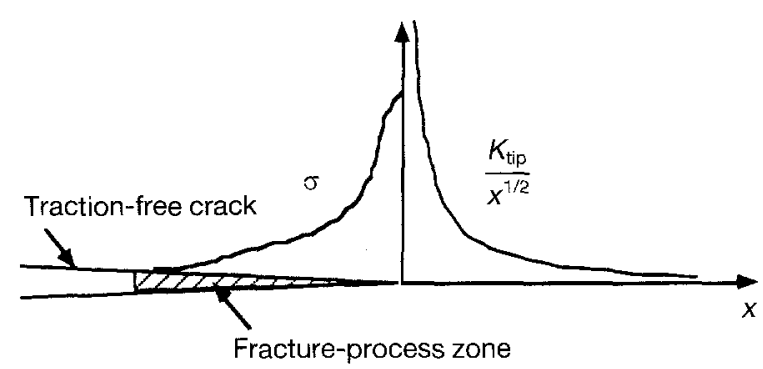

(a)

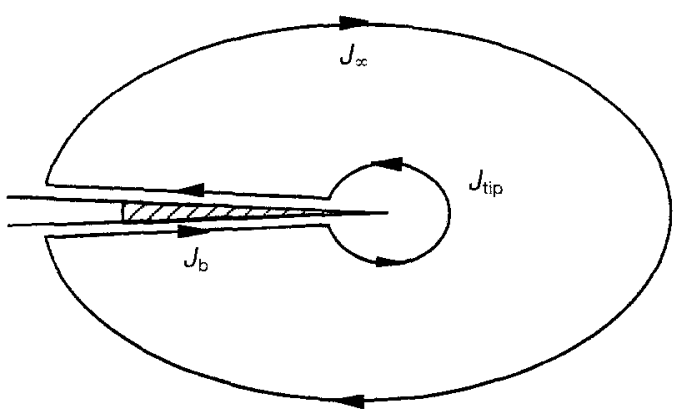

(b)

Figure 1 (a) A schematic plot of the stress distribution, and (b) the $J$-integral contour used for derivation of Equation 2. of Hillerborg [4]. For the closed contour shown in Fig. $1 b$, the $J$-integral path-independent property [12] requires

$$
J_{\infty}+J_{\mathrm{b}}+J_{\mathrm{tip}}=0
$$

The $J_{\infty}$-term represents the energy-release rate associated with far-field loading, and it contains information on the specimen geometry and applied load. $J_{\text {tip }}$ is the crack-tip singularity term. Finally, $J_{\mathrm{b}}$ is the energy consumed by the development of the fracture-process zone. Applying the $J$-integral analysis to the terms $J_{\text {ip }}$ and $J_{\mathrm{b}}$ for the material with the crack-tip singularity and fracture-process zone, Equation 1 can be expressed by

$$
J_{\infty}=\int_{0}^{\delta_{\mathrm{t}}} \sigma(\delta) \mathrm{d} \delta+\frac{K_{\mathrm{tip}}^{2}\left(1-v^{2}\right)}{E}
$$

where $\delta_{t}$ is the crack-opening displacement measured at the original crack tip, $K_{\text {tip }}$ is the crack-tip stress intensity factor, and $E$ and $v$ are the composite's Young's modulus and Poisson's ratio, respectively. Differentiating Equation 2 with respect to $\delta_{t}$, the stress, $\sigma$, may then be determined from

$$
\sigma\left(\delta_{\mathrm{t}}\right)=\frac{\partial}{\partial \delta_{\mathrm{t}}}\left[J_{\infty}\left(\delta_{\mathrm{t}}\right)-\frac{K_{\mathrm{tip}}^{2}\left(1-v^{2}\right)}{E}\right]
$$

When $K_{\text {tip }}$ reaches the crack-tip toughness $K_{0}$, the fracture-process zone starts to grow according to the $\sigma-\delta$ relationship. Thus if $J_{\infty}$ and $K_{0}$ can be determined, and $\delta_{t}$ can be obtained experimentally, then the $\sigma-\delta$ relationship can be derived from Equation 3 . The $J$-integral value, $J_{\infty}$, can be evaluated experimentally by conducting tests on a pair of specimens with differential notch lengths. Furthermore, the determination of the crack-tip toughness, $K_{0}$, can be obtained from the initial value of $R$-curves.

\section{Experimental methods}

The materials used in this study were high-strength mortar (HSM) and fibre-reinforced HSM. The dimensions and mechanical properties of the fibres used for reinforcement are given in Table $I$. The constituent materials of the matrix and their mix proportions are given in Table II. Type I Portland cement, silica sand (with a maximum grain size of $0.6 \mathrm{~mm}$ ), silica fume and superplasticizer were used to form a HSM with a

TABLE I The dimensions and mechanical properties of fibres

\begin{tabular}{llllll}
\hline Fibre & $\begin{array}{l}\text { Fibre } \\
\text { diameter } \\
(\mu \mathrm{m})\end{array}$ & $\begin{array}{l}\text { Fibre } \\
\text { length } \\
(\mathrm{mm})\end{array}$ & $\begin{array}{l}\text { Elastic } \\
\text { modulus } \\
(\mathrm{GPa})\end{array}$ & $\begin{array}{l}\text { Fibre } \\
\text { strength } \\
(\mathrm{MPa})\end{array}$ & $\begin{array}{l}\text { Fibre density } \\
\left(\mathrm{kg} \mathrm{m}^{-3}\right)\end{array}$ \\
\hline Steel & 150 & 6 & 200 & 2500 & 7800 \\
Carbon & 9.6 & 12.5 & 241 & 2800 & 2100 \\
\hline
\end{tabular}

TABLE II Mortar mix proportions (by weight)

\begin{tabular}{lllll}
\hline Cement & Sand & Silica fume & Superplasticizer & Water \\
\hline 1.00 & 0.75 & 0.10 & 0.02 & 0.27 \\
\hline
\end{tabular}


water/cementitious ratio of 0.27 . The compressive strength determined from three cylindrical specimens was $85.5 \mathrm{MPa}$. Carbon and steel fibres were used for reinforcing the matrix (with a fibre volume fraction of $1.5 \%$ for the carbon fibres, and $0.17 \%$ and $1.0 \%$ for the steel fibres).

The compact tension (CT) specimen illustrated in Fig. 2 was used to determine the $\sigma-\delta$ relationship of the materials by means of the $J$-based testing technique. An artificial notch with a root radius of $250 \mu \mathrm{m}$ was introduced into each specimen. As a supplement to the $J$-based tests, uniaxial-tension tests were conducted on rectangular tensile specimens with a crosssection of $76 \times 13 \mathrm{~mm}^{2}$. The specimens were cast in Plexiglass moulds using a high-frequency vibration $(150 \mathrm{~Hz})$ in order to improve the packing of the material and to reduce air entrapment. After casting, they were allowed to harden at room temperature for one day prior to demoulding and then they were cured in water for four weeks before testing.

The fracture-toughness tests and uniaxial-tension tests were conducted in a hydraulic servo-controlled testing machine. The specimens were loaded to complete failure with a constant crosshead speed; the testing time was typically $10 \mathrm{~min}$ for all tests. The load, $P$, load-line displacement, $\delta_{\mathrm{L}}$, and crack-tip-opening displacement, $\delta_{t}$; were monitored continuously. $\delta_{L}$ and $\delta_{\mathrm{t}}$ were measured using linear-variable differential transducers (LVDTs). As is shown schematically in Fig. 2, a pair of LVDT holders were glued on the side surfaces of the specimen at the pre-notch tip. The relative displacement between the holders was measured on both specimen sides using LVDTs, and the two displacement values were averaged to determine $\delta_{\mathrm{t}}$. In some fracture-toughness tests, $R$-curve measurements were carried out using an unloading compliance method. Unloading and reloading cycles produced non-linear deformation, resulting in a significant hysteresis loop. Thus, a linearization procedure proposed in [13] was used to determine the specimen compliance. During the uniaxial tests, the relative displacement between two points along the loading axis was monitored to measure the elongation. The gauge length for the measurement was approximately $200 \mathrm{~mm}$.

\section{Results and discussion}

In this section, the $J$-based technique briefly outlined above is applied to the experimental data for the HSM composites. In order to demonstrate the data-analysis procedure of the $J$-based technique, a set of experimental results for the carbon-fibre-reinforced HSM is presented first.

Fig. $3 a$ shows average load versus load-line displacement curves for each crack length. Each curve represents an average of three repeated tests. Fig. $3 b$ shows the relationship between the load-line displacement and the crack-tip-opening displacement (CTOD). The $J$-integral value is calculated from the set of $P / B-\delta_{\mathrm{L}}$ curves (Fig. 3a) using the equation

$$
J_{\infty}\left(\delta_{\mathbf{L}}\right)=\frac{1}{\left(a_{2}-a_{1}\right)} \int_{\circ}^{\delta_{\mathbf{L}}}\left(\frac{P_{1}}{B}-\frac{P_{2}}{B}\right) \mathrm{d} \delta_{\mathrm{L}}
$$
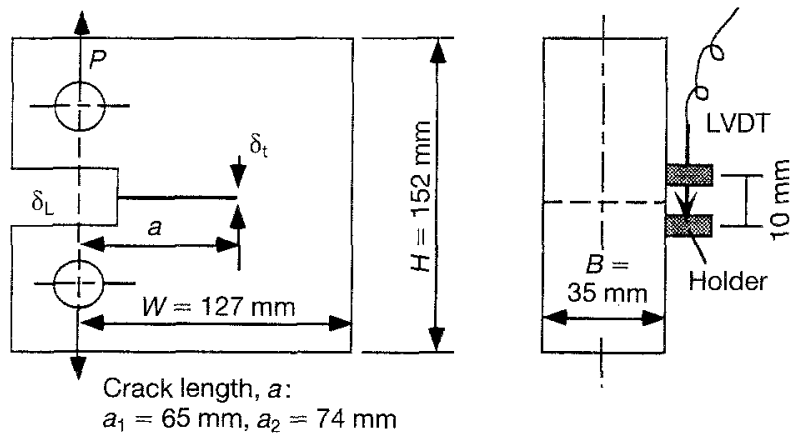

Figure 2 CT-specimen geometry and dimensions (LVDT, linearvariable differential transducer)
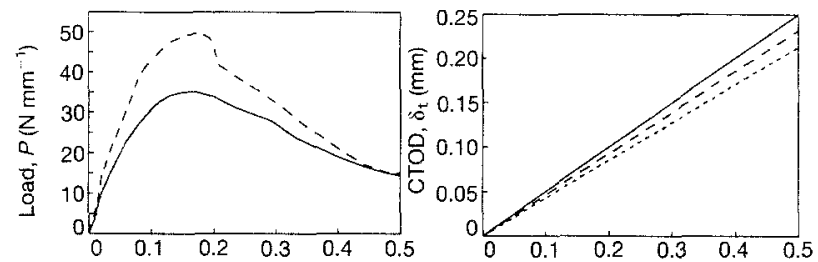

(a) Load-line displacement, $\delta_{\llcorner}(\mathrm{mm})$
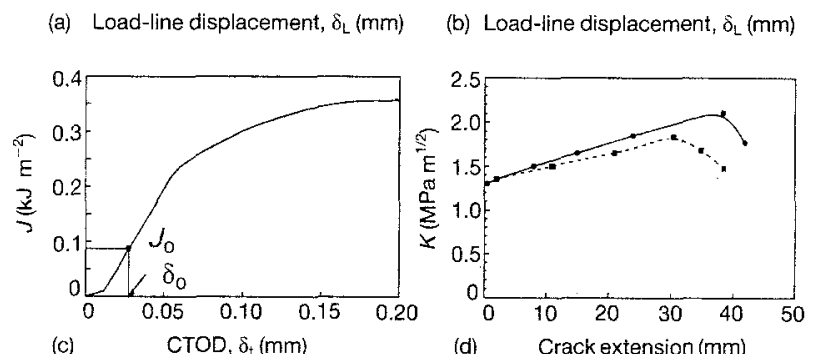

Figure 3 (a) Load versus displacement: (-- ) $a_{1}=65 \mathrm{~mm}$ and (-) $a_{2}=74 \mathrm{~mm}$. (b) CTOD versus load-line displacement: ( $\longrightarrow$ ) $a_{1}=65 \mathrm{~mm},(--) a_{2}=74 \mathrm{~mm}$, and (- - ) the average of $a_{1}$ and $a_{2}$. (c) $J$-integral versus CTOD. (d) $K$-resistance curve: (-) $a_{1}=65 \mathrm{~mm}$ and $(---) a_{2}=74 \mathrm{~mm}$. (All with $1.5 \%$ carbon-fibre HSM).

The result is plotted against the average CTOD in Fig. 3c. The total $J$-integral value is $0.36 \mathrm{~kJ} \mathrm{~m}^{-2}$. The $R$-curve approach is used to determine the crack-tip toughness, $K_{0}$. An example of $K$-resistance curves is shown in Fig. 3d. The dimensionless specimen compliance and $K$ formula for the CT specimen were taken from Newman's boundary collocation analysis [14] to construct the $K$-resistance curves. The initial value of the curve $\left(1.33 \mathrm{MPa} \mathrm{m}^{1 / 2}\right)$ represents the critical stress intensity factor for advancing the crack against the modified matrix toughness, and thus it can be taken as the crack-tip toughness. Note that the decrease of the $K$-resistance curve at large crack extensions may be attributed to the crack propagation into the compression zone of the CT specimens. The $J_{0}$-value converted from the $K_{0}$-value using the equation $J_{0}=K_{0}^{2}\left(1-v^{2}\right) / E$ is indicated in the $J$ versus $\delta_{t}$ plot in Fig. 3c. An experimental value of the effective Young's modulus, $20.5 \mathrm{GPa}$, was used in the calculation. It should be noted that the crack-tip toughness accounts for approximately one-quarter of the total toughness.

As in the original $J$-based technique [5], $J\left(\delta_{t}\right)$ is differentiated with respect to $\delta_{t}$ to obtain the bridgingstress-crack-opening-displacement curve, shown in 


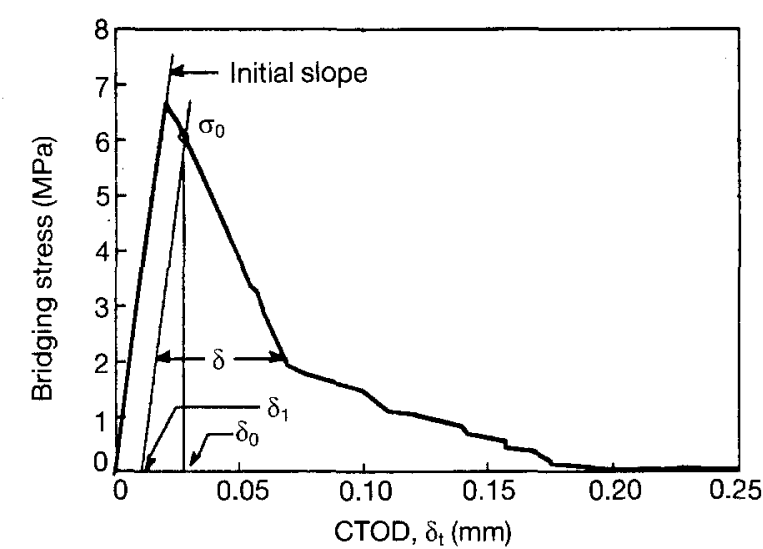

Figure 4 Bridging stress versus CTOD curve for $1.5 \%$ carbon-fibre HSM.

Fig. 4. The $\sigma-\delta_{\mathrm{t}}$ curve initially rises to a peak, then it decreases with increasing $\delta_{\mathrm{t}}$. The rising portion of the curve is due to the presence of a strain between the LVDT holders. It can be interpreted as the sum of the elastic deformation and the distributed damage prior to localization of inelastic deformation onto the fracture-process zone, and therefore it should not be regarded as part of the bridging-stress-crack-openingdisplacement relation [5]. In Fig. 3c, $\delta_{0}$ represents the measured CTOD corresponding to the crack-tip toughness. This value defines a point $\left(\delta_{0}, \sigma_{0}\right)$ on the $\sigma-\delta_{t}$ curve (Fig. 4) through which a straight line parallel to the curve initial slope can be drawn. The portion of the $\sigma-\delta_{t}$ curve to the right of this line represents the true $\sigma-\delta$ curve. Numerically, the true $\sigma-\delta$ curve can be deduced from the $\sigma-\delta_{\mathrm{t}}$ curve by applying the following correction to the crack opening,

$$
\delta=\delta_{\mathrm{t}}-\left[\delta_{1}+\frac{\delta_{0}-\delta_{1}}{\sigma_{0}} \sigma\left(\delta_{\mathrm{t}}\right)\right] \quad\left(\text { for } \delta_{\mathrm{t}} \geqslant \delta_{0}\right)
$$

where $\delta_{1}$ is indicated in Fig. 4. Fig. 5 shows the corrected $\sigma-\delta$ curve, together with the result for the matrix alone, that is, for the HSM. The energy absorption of the carbon fibre in the post-peak region is higher than in the mortar. Microscopic observation of fracture surfaces showed that the fracture behaviour of the carbon fibre HSM is dominated by fibre rupture, and limited pull-out of the fibre was observed. Thus the higher bridging toughness of the carbon fibre HSM (with respect to HSM) may be attributed to this fibre pull-out. The experimental results regarding the

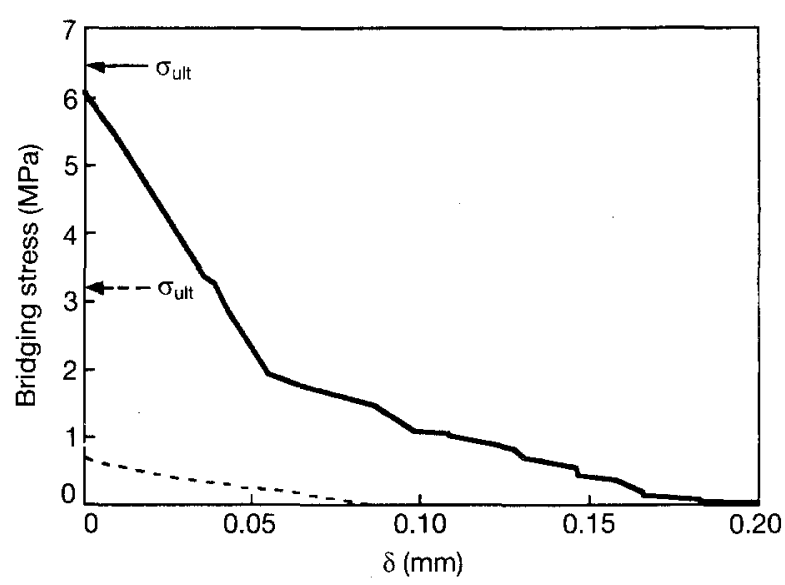

Figure 5 Deduced tension-softening curve for: (--) HSM, and $(\longrightarrow) 1.5 \%$ carbon fibre HSM.

$J$-based tests for all materials are summarized in Table III. In order to characterize the type of materials, the ratio of the crack-tip toughness to the total toughness, $J_{0} / J_{\mathrm{c}}$, is indicated in Table III.

Using the stroke-control mode with the uniaxial-tensile test, no tension-softening behaviour was registered for the HSM and the carbon-fibre-HSM specimens. However, for each one of these materials, we expect the ultimate tensile strength to give an upper-bound value for the peak stress of the corresponding $\sigma-\delta$ curve. Fig. 5 shows that this is indeed the case. Moreover, evidence supporting the validity of the present $J$-based testing procedure can be observed in the steel-fibre-HSM composites where the postpeak behaviour is dominated by fibre pull-out.

A set of experimental results used in the computation of the $\sigma-\delta_{t}$ curve for the $0.17 \%$ steel-fibreHSM composite is shown in Fig. 6. Uniaxial-tensile curves obtained for the steel-fibre-HSM composites, showed that the post-crack strength is lower than the ultimate strength. For composites where the ultimate strength is higher than the post-crack strength, there is the possibility of an underestimation of the post-peak composite strength, $\sigma_{p c}$. A theoretical model for the $\sigma-\delta$ relationship [15] based on the frictional fibre pull-out mechanism predicts that the post-peak composite strength is $0.66 \mathrm{MPa}$ for the $0.17 \%$ steelfibre-HSM and it is $3.89 \mathrm{MPa}$ for the $1 \%$ steelfibre-HSM (assuming an interfacial frictional bond strength of $10 \mathrm{MPa}$, and a snubbing coefficient of 0.8 [15]). The experimentally determined post-crack strength is close to the theoretical prediction. This may indicate that the observed post-crack strength

TABLE III A summary of the experimental results

\begin{tabular}{|c|c|c|c|c|c|c|c|}
\hline Material & $\begin{array}{l}\text { Fibre volume } \\
\text { fraction }(\%)\end{array}$ & $\begin{array}{l}\text { Tensile } \\
\text { strength }^{\mathbf{a}} \\
\sigma_{\mathrm{uth}}(\mathrm{MPa})\end{array}$ & $\begin{array}{l}\text { Post-cracking } \\
\text { strength }^{\mathrm{a}} \\
(\mathrm{MPa})\end{array}$ & $\begin{array}{l}\text { Effective } \\
\text { Young's } \\
\text { modulus } \\
(\mathrm{GPa})\end{array}$ & $\begin{array}{l}\text { Crack-tip } \\
\text { toughness } \\
J_{0}\left(\mathrm{~kJ} \mathrm{~m}^{-2}\right)\end{array}$ & $\begin{array}{l}\text { Total } \\
\text { toughness } \\
J_{\mathrm{c}}\left(\mathrm{kJ} \mathrm{m}^{-2}\right)\end{array}$ & $\frac{J_{0}}{J_{\mathfrak{c}}}$ \\
\hline HSM & 0 & 3.21 & - & 20.20 & 0.017 & 0.035 & 0.49 \\
\hline Carbon-fibre HSM & 1.5 & 6.48 & - & 20.52 & 0.086 & 0.36 & 0.24 \\
\hline Steel-fibre HSM & 0.17 & 3.43 & 0.82 & 19.70 & 0.019 & 0.47 & 0.04 \\
\hline Steel-fibre HSM & 1 & 4.02 & 3.75 & 20.50 & 0.019 & 4.75 & 0.004 \\
\hline
\end{tabular}

${ }^{a}$ Results of uniaxial-tension tests. 
provides a good estimate of the true $\sigma_{\mathrm{pc}}$-value. It should be particularly noted in Figs 7 and 8 that the deduced peak stress is close to the post-peak composite strength obtained from the uniaxial-tension tests. Moreover, it can be seen from the inset in Fig. 7 that, if the crack-tip toughness is neglected, the peak

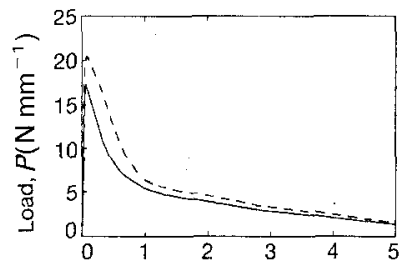

(a) Load-line displacement, $\delta_{1}(\mathrm{~mm})$

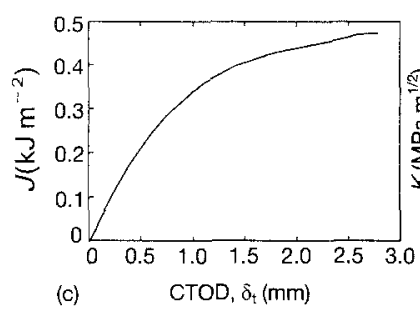

Figure 6 (a) Load versus displacement: $(---) a_{1}=65 \mathrm{~mm}$ and (- $-a_{2}=74 \mathrm{~mm}$. (b) CTOD versus load-line displacement: ( $\longrightarrow$ ) $a_{1}=65 \mathrm{~mm},(--) a_{2}=74 \mathrm{~mm}$, and (- - - ) the average of $a_{1}$ and $a_{2}$. (c) $J$-integral versus CTOD. (d) $K$-resistance curve: $(-)$ $a_{1}=65 \mathrm{~mm}$ and $(---) a_{2}=74 \mathrm{~mm}$. (All with $0.17 \%$ steel-fibre HSM).

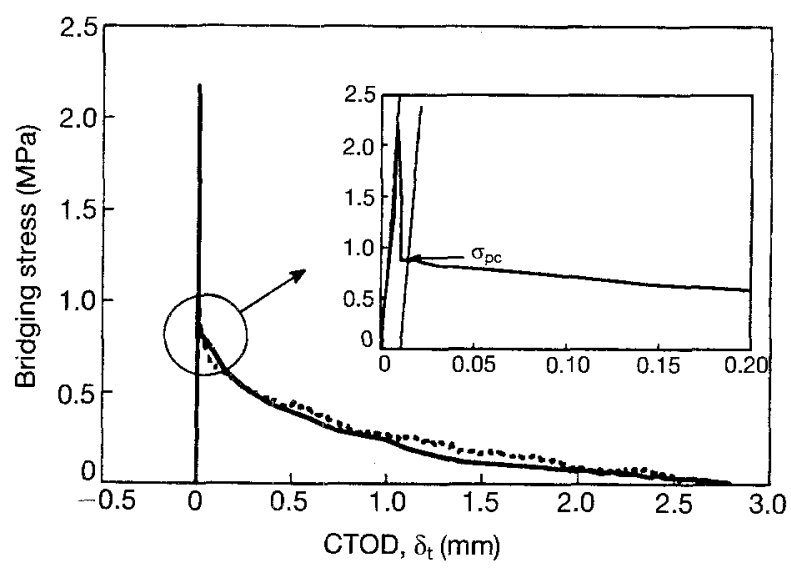

Figure 7 Bridging stress versus CTOD for a $0.17 \%$ steel-fibre HSM: (- $J$-based result, and ( ...) uniaxial-tension result.

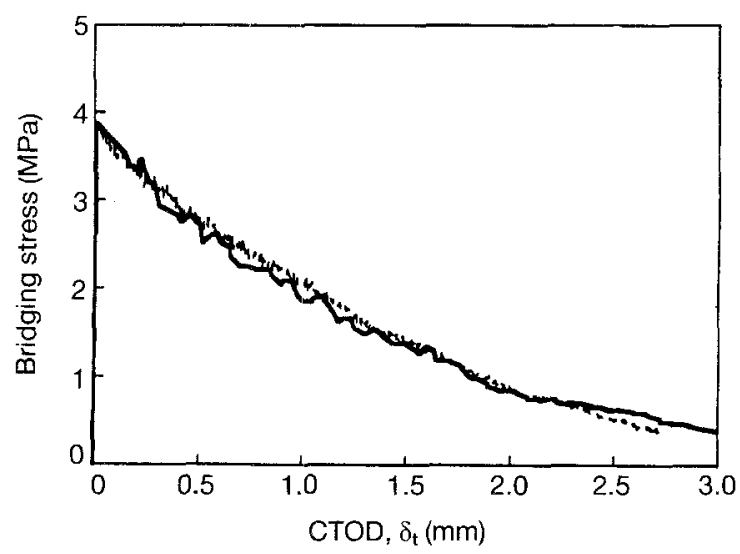

Figure 8 Bridging stress versus CTOD for a $1.0 \%$ steel-fibre HSM: $(-J$-based result, and $(\cdots)$ uniaxial-tension result. stress of the $\sigma-\delta$ curve deduced from the $J$-based method corresponding to the $0.17 \%$ steel-fibre HSM will be significantly overestimated. Table III indicates that, for this particular material, the ratio of the cracktip toughness to the total toughness is about $4 \%$.

It is therefore important to account for the crack-tip toughness in the determination of accurate $\sigma-\delta$ relationships in materials for which the ratio $J_{0} / J_{\mathrm{c}}$ is nonnegligible. For the $1.0 \%$ steel-fibre-HSM composite where the crack-tip toughness is only $0.4 \%$ of the total toughness, the original $J$-based technique can provide a good estimate of the true $\sigma-\delta$ curve.

On the basis of the above observations, the experimental data of the bridging stress and the crack-tip toughness appear to be sufficient parameters for characterizing the fracture behaviour of fibre-reinforced HSM. Furthermore, the two characterizing parameters can be readily incorporated into numerical simulation codes, such as FEM (finite element method) and BEM (boundary element method), for analyses of fracture in fibre-reinforced high-strength concrete. Therefore, it is expected that the present $J$ based technique provides a basis for the fracture analysis of real structural components.

\section{Conclusion}

The $J$-based fracture-testing technique has been newly extended in order to cover HSM and its fibrereinforced composites where the crack-tip toughness is comparable to the bridging toughness due to fracture-process-zone development. This method is even more essential for fibre-reinforced high-strength concrete where the crack-tip toughness can be considerably higher than in normal-strength concrete. On the basis of the $J$-integral analysis of the fractureprocess zone with a crack-tip singularity, a testing procedure has been developed to determine the bridging-stress-crack-opening-displacement relation $(\sigma-\delta)$. This new technique has been applied to the experimental results of fracture tests conducted on HSMs reinforced with carbon and steel fibres. The $\sigma-\delta$ relationships deduced from the $J$-based technique have been compared with results of uniaxial-tensile tests and good agreements have been obtained, supporting the validity of the extended $J$-based fracture-testing method.

\section{Acknowledgements}

This research was supported by a research grant from the National Science Foundation (BCS 92020 97) to the University of Michigan, Ann Arbor, USA.

\section{References}

1. S. P. SHAH, Mater. Structures 21 (1988) 145

2. M. WECHARATANA and S. CHIMAMPHANT, in "Bonding in cementitious composites", Materials Research Society Symposium Volume, edited by S. Mindess and S. P. Shah (Materials Research Society, Pittsburgh, 1988) p. 114.

3. G. TOGNON and S. CANGIANO, in "Fracture toughness and fracture energy-test methods for concrete and rock", edited by $H$. Mihashi, $H$. Takahashi and $H$. Wittmann (Balkema, Rotterdam, 1989) p. 57. 
4. A. HILLERBORG, in "Fracture mechanics of concrete", edited by F. H. Wittman (Elsevier, Amsterdam, 1983) p. 223.

5. V. C. LI, C. M. CHAN and C. K. Y. LEUNG, Cement Concrete Res. 17 (1987) 441.

6. S. TERAMURA, N. NOMURA, T. HASHIDA, H. TAKAHASHI and H. MIHASHI, in "Micromechanics of failure of quasi-brittle materials", edited by S. P. Shah, S. E. Swartz and M. L. Wang (Elsevier Applied Science, London, 1990) p. 463.

7. V. C. LI and R. WARD, in "Fracture toughness and fracture energy-test methods for concrete and rock", edited by $\mathbf{H}$. Mihashi, H. Takahashi and H. Wittmann (Balkema, Rotterdam, 1989) p. 183.

8. C. K. Y. LEUNG and V. C. LI, J. Mater. Sci, 24 (1989) 854

9. K. ROKUGO, M. IWASA, S. SEKO and W. KOYANAGI, in "Fracture of concrete and rock, recent developments", edited by S. P. Shah, S. E. Swartz and B. Barr (Elsevier, London, 1989) p. 513.
10. T. HASHIDA, in "Micromechanics of failure of quasi-brittle materials", edited by S. P. Shah, S. E. Swartz and M. L. Wang (Elsevier Applied Science, London, 1990) p. 233.

11. K. P. CHONG, V. C. LI and H. H. EINSTEIN, Engng. Fract. Mech. 34 (1989) 669.

12. J. R. RICE, J. Appl. Mech. 35 (1968) 379.

13. International Society for Rock Mechanics, Int. J. Rock Mech. Min. Sci. 25 (1988) 71.

14. J. C. NEW M AN, Jr. "Stress analysis of the compact specimen including the effects of pin loading", ASTM STP 560 (American Society for Testing and Materials, Philadelphia, 1974) p. 105.

15. V. C. LI, J. Mater. Civil Engng 4 (1992) 41.

\section{Received 1 October 1992}

and accepted 8 October 1993 